\title{
Comparison Between Nasal High-Frequency Oscillatory Ventilation And Nasal Continuous Positive Airway Pressure In The Management Of Respiratory Distress Syndrome
}

I.A.Ramadan, A.M.Shaheen and S.A.Abd El-Maksoud

Pediatrics, Dept., Faculty of Medicine, Benha Univ., Benha, Egypt

E-mail:mosad8rashed@gmail.com

\begin{abstract}
Context: A neonatal respiratory distress syndrome occurs at or soon after delivery $(<24$ hours). Premature newborns with respiratory distress syndrome (RDS) often need breathing assistance. There has been a tendency to reduce in the previous decade the use of non-invasive ventilation modes (NIV) in neonatal intensive care units to prevent ventilator-induced lung damage, in particular after recent data showing NIV in preterm babies has equivalent efficiency compared to EMV. In practical practise, different forms of NIV may be employed include nasal continuing positive airway pressure and noninvasive intermittent positive airway pressure. Nasal continuous positive airway pressure is one of the most often utilised non-invasive techniques (NCPAP). Although HFV has been used in several neonatal critical care units, a relatively novel modality of nasal high frequency oscillatory ventilation (nHFOV) is limited in evidence of its utility. The objective of this research has been to examine the effectiveness and safety of nasal oscillatory ventilation with nasal airway continuous pressure in preterm baby respiratory distress syndrome therapy. Methods: This research is a (60 instances) clinical experiment conducted with respiratory distress syndrome (admitted to the Benha University Hospital Neonatal Intensive Care Unit and Benha Kids Hospital) between the 1-28 day age range. Cases were randomly picked in two groups: Group I: 30 instances of high-frequency oscillatory nasal ventilation were treated (nHFOV). Group II: 30 individuals with constant nasal airway pressure were treated (NCPAP). Methods: Detailed history of medicine. Total usage time NHFV and NCPAP usage time and oxygenation time required for each instance. Complication detection occurs during non-invasive breathing (pulmonary air leak syndrome, IVH, nasal injury and other.) Studies of imagery. Outcomes: There was no statistically significant difference in demographic data between the two groups. There was a statistically significant difference in IVH complication between Group I and Group II. The percentage of nasal septal injuries in Group I was significantly lower than in Group II. The rate of intervention failure (intubing and ventilator demand) in Group I was significantly lower than in Group II (3.3 percent, (26.6 percent) p value $=0.030$. Conclusion: High frequency nasal ventilation has a greater impact than continuous airway pressure on infants and is less complicated. This research revealed that the length of non-invasive respiratory support was greatly shortened by high frequency nasal ventilation and the necessity for intubation was minimised compared to the continuous positive airway pressure of RDS infants.
\end{abstract}

Keywords: Nasal high frequency oscillatory ventilation, Nasal continuous airway pressure, Respiratory distress syndrome, Preterm infants.

\section{Introduction}

ARS is one of the leading causes of death in preterm infants [1].

Premature newborns with respiratory distress syndrome (RDS) often need breathing assistance. In the recent decade, efforts have been made to adopt noninvasive approaches in the care of these patients due to the problems of intubation and mechanical breathing. [2] Nasal ventilation has been employed during the last couple of decades to manage and improve respiratory failure in RDS newborns. Nasal continuous positive airway pressure is one of the most often utilised noninvasive techniques (NCPAP). NCPAP is a reasonably easy and successful treatment for early RDS control in neonates [3].

NCPAP is the application of positive pressure throughout the respiratory cycle in the airways of breathing newborns. However, some newborns can suffer respiratory failure and need mechanical ventilator assistance with this treatment method. Some studies indicate that $43 \%-80 \%$ of neonates with moderate to severe respiratory failure who first receive NCPAP require mechanical ventilation $[4,5]$.
In recent years, the favourable benefits of high frequency fans in the RDS management and the employment of these fans as a form of support or rescue following a breakdown in traditional mechanical ventilation have been shown [6].

A low tidal volume with a greater frequency than natural breathing is achieved in high-frequency ventilation (HFV). [7] This technology is particularly successful in carbon dioxide (CO2) elimination and is free from dead space. [8] The key function in this mechanical mode is the adequate recruitment of lung volume as well as the promotion of surfactant treatment [9].

Although HFV has been used in several neonatal critical care units, a relatively novel modality of nasal high frequency oscillatory ventilation (nHFOV) is limited in evidence of its utility. [10] In a model involving newborn manikins, nHFOV is successful and superior to intermittent, positive nasal pressure ventilation in terms of lung removal $\mathrm{CO} 2$. The $\mathrm{nHFOV}$ is a non-invasive ventilation method that uses a nasal interface to apply oscillatory pressure waveform on the airways. This technique has been shown to promote 
$\mathrm{CO} 2$ expiry, but its application in newborns is unknown [11].

There are growing data that nHFOV has positive benefits in lowering respiratory distress in comparison with NCPAP's RDS effects [12].

The purpose of the research was to examine the effectiveness and safety of high frequency nasal oscillatory ventilation versus nasal continuous airway pressure in preterm children with respiratory distress syndrome.

\section{Patients and Methods}

\subsection{Patients}

Subjects

This is a clinical prospective study trial which was done on (60 cases) with respiratory distress syndrome (who are admitted in the neonatal intensive care unit at Benha University Hospital and Benha children hospital) in the age group of 1-28 days done from 11 May 2020 to 10 April 2021.

Cases were divided into two groups randomly selected:

- Group I: 30 cases were treated with nasal highfrequency oscillatory ventilation (nHFOV).

- Group II: 30 cases were treated with nasal continuous airway pressure (NCPAP).

\subsection{Inclusion criteria}

Infants in neonatal period.

Gestational age: preterm infants ( $<37$ weeks). Both sexes were included.

Any case with respiratory distress syndrome from 1 to 28 days.

\subsection{Exclusion criteria}

- Neonates born with congenital anomalies.

\subsection{Methods}

\section{Detailed medical history.}

- personal history (name, age, sex, residence)

- history of present illness (onset, course, duration, associated symptoms)

- past history (history of previous operations , ...)

- family history (history of chronic illness gestational diabetes-HTN-consanguinity-other siblings-similar conditions in family)

2. Detailed clinical examination (gestational age , birth weight, gender, APGAR score, grade of respiratory distress).

3. Laboratory investigation including

- Complete blood count.

- C-reactive protein.

4. Blood gases, oxygen saturation and fio2 value during the time of treatment.

5. Total time of use NHFV and time of use NCPAP and time needed for oxygenation for each case.

6. Detection of complication appears during noninvasive ventilation (pulmonary air leak syndrome, IVH, nasal injury and other.)
7. Imaging studies

*Chest x-ray.

*Cranial ultra sonograghy.

\subsection{Ethical considerations}

Informed consents were obtained from all cases guardians included in this study which were approved by the local ethical committee of Benha University.

\subsection{Statistical analysis}

The data were coded, entered and processed on computer using Statistical package for social science (SPSS) (version24).The results were represented in tabular and diagrammatic forms then interpreted.

Mean, standard deviation, range, frequency, and percentage were use as descriptive statistics.

The following test was done:

- Chi-Square test $\mathbf{X}^{2}$ was used to test the association variables for categorical data.

- Fisher's exact test is used when you have two nominal variables. Fisher's exact test is more accurate than the chi-squared test when the expected numbers are small.

- Student's t-test was used to assess the statistical significance of the difference between two population means in a study involving independent samples.

The accepted level of significance in this work was stated at 0.05 ( $\mathrm{P}<0.05$ was considered significant),.P value $>0.05$ is non significant $(\mathrm{N}-\mathrm{S})$

Mean $=$ Is the sum of the values in a set of data divided by the number of the values in the set.

Standard deviation (SD)

It is the positive square root of the variance.

Variance $=\mathbf{S}^{\mathbf{2}}$

The sum of the squares of the deviation of each measurement in a series from the mean of the series, divided by the total number of the observation minus one. (The degree of freedom) [13].

\section{Results}

- There was no statistically significant difference between Group I and Group II regarding demographic data Table (1).

- Mean value of Duration of treatment was statistically lower among group I than group II $(2.60,3.63) \mathrm{p}$ value $=0.003$ Table (2).

- Table (3) and figure (1) show that the percentage of Failure of intervention (need for intubation and ventilator) was statistically lower among group I than group II $(3.3 \%,(26.6 \%) \mathrm{p}$ value $=0.030$.

- There was statistically significant difference between Group I and Group II regarding IVH complication. Percentage of was IVH as a complication was statistically significant lower among group I than group II Table (4).

- Table (5) and figure (2) show that the percentage of presence of nasal septum injury was statistically lower among group I than group II $(30 \%,(60 \%) \mathrm{p}$ value $=0.020$. 
Table (1) Comparison between Group I and Group II regarding demographic data.

\begin{tabular}{|c|c|c|c|c|c|c|}
\hline & & & $\begin{array}{c}\text { Group I } \\
(\text { No.= 30) }\end{array}$ & $\begin{array}{l}\text { Group II } \\
(\text { No.= 30) }\end{array}$ & $\mathbf{X}^{2}$ & P. value \\
\hline \multirow{2}{*}{ Sex } & Female & $\begin{array}{l}\text { No. } \\
\%\end{array}$ & $\begin{array}{c}12 \\
40.0 \%\end{array}$ & $\begin{array}{c}10 \\
33.3 \%\end{array}$ & \multirow[t]{2}{*}{0.287} & \multirow[t]{2}{*}{0.592} \\
\hline & Male & $\begin{array}{l}\text { No. } \\
\%\end{array}$ & $\begin{array}{c}18 \\
60.0 \%\end{array}$ & $\begin{array}{c}20 \\
66.7 \%\end{array}$ & & \\
\hline \multirow{2}{*}{ Mode of delivery } & CS & $\begin{array}{l}\text { No. } \\
\%\end{array}$ & $\begin{array}{c}18 \\
60.0 \%\end{array}$ & $\begin{array}{c}19 \\
63.3 \%\end{array}$ & \multirow[t]{2}{*}{0.071} & \multirow[t]{2}{*}{0.790} \\
\hline & NVD & $\begin{array}{l}\text { No. } \\
\%\end{array}$ & $\begin{array}{c}12 \\
40.0 \%\end{array}$ & $\begin{array}{c}11 \\
36.6 \%\end{array}$ & & \\
\hline Age in Days & \multicolumn{2}{|c|}{ Mean \pm SD } & $3.03 \pm 2.76$ & $2.83 \pm 1.59$ & $\begin{array}{c}\text { t.test } \\
2.060\end{array}$ & 0.244 \\
\hline
\end{tabular}

Table (2) Comparison between Group I and Group II regarding Duration of treatment.

\begin{tabular}{|c|c|c|c|c|c|}
\hline & & $\begin{array}{c}\text { Group I } \\
(\text { No.= 30) }\end{array}$ & $\begin{array}{l}\text { Group II } \\
(\text { No.= 30) }\end{array}$ & t.test & P. value \\
\hline $\begin{array}{l}\text { Duration of } \\
\text { treatment (days) }\end{array}$ & Mean \pm SD & $2.60 \pm .770$ & $3.63 \pm 1.69$ & $-3.045-$ & .003 \\
\hline
\end{tabular}

Table (3) Comparison between Group I and Group II regarding Failure of intervention.

\begin{tabular}{|c|c|c|c|c|c|c|}
\hline & & & $\begin{array}{c}\text { Group I } \\
(\text { No. }=30)\end{array}$ & $\begin{array}{l}\text { Group II } \\
(\text { No.= 30) }\end{array}$ & $\mathbf{X}^{2}$ & P. value \\
\hline $\begin{array}{l}\text { Failure of } \\
\text { intervention (need } \\
\text { for intubation and } \\
\text { ventilator) }\end{array}$ & $\begin{array}{l}\text { Yes } \\
\text { No }\end{array}$ & $\begin{array}{l}\text { No. } \\
\% \\
\text { No. } \\
\%\end{array}$ & $\begin{array}{c}1 \\
3.3 \% \\
29 \\
96.6 \%\end{array}$ & $\begin{array}{c}8 \\
26.6 \% \\
22 \\
73.3 \%\end{array}$ & 4.706 & 0.030 \\
\hline
\end{tabular}

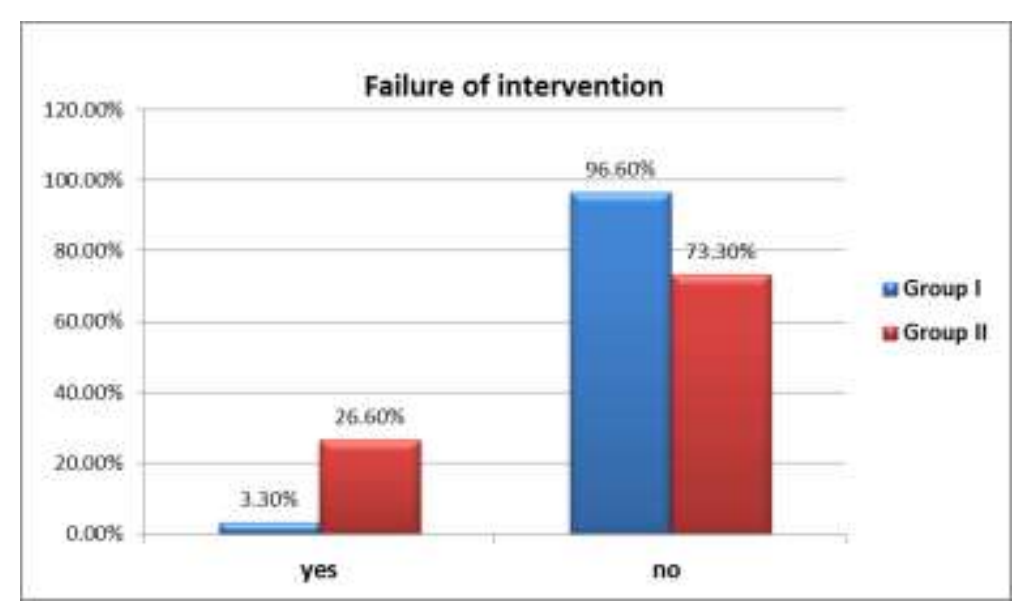

Fig. (1) Comparison between Group I and Group II regarding Failure of intervention.

Table (4) Comparison between Group I and Group II regarding IVH complication.

\begin{tabular}{lllcccc}
\hline & & & $\begin{array}{c}\text { Group I } \\
(\text { No.= 30) }\end{array}$ & $\begin{array}{c}\text { Group II } \\
(\text { No.= 30) }\end{array}$ & X $^{2}$ & P. value \\
\hline & Yes & No. & 1 & 7 & & \\
IVH complication & & $\mathbf{\%}$ & $3.3 \%$ & $23.3 \%$ & 3.606 & 0.04 \\
& No & No. & 29 & 23 & $76.6 \%$ & \\
\hline
\end{tabular}


Table (5) Comparison between Group I and Group II regarding Nasal septum Injury.

\begin{tabular}{|c|c|c|c|c|c|c|}
\hline & & & $\begin{array}{c}\text { Group I } \\
(\text { No.= 30) }\end{array}$ & $\begin{array}{l}\text { Group II } \\
(\text { No.= 30) }\end{array}$ & $\mathrm{X}^{2}$ & P. value \\
\hline $\begin{array}{l}\text { Nasal septum } \\
\text { Injury }\end{array}$ & $\begin{array}{l}\text { presence of } \\
\text { injury } \\
\text { absence of } \\
\text { injury }\end{array}$ & $\begin{array}{l}\text { No. } \\
\% \\
\text { No. } \\
\%\end{array}$ & $\begin{array}{c}9 \\
30.0 \% \\
21 \\
70.0 \%\end{array}$ & $\begin{array}{c}18 \\
60.0 \% \\
12 \\
40.0 \%\end{array}$ & 5.455 & .020 \\
\hline
\end{tabular}

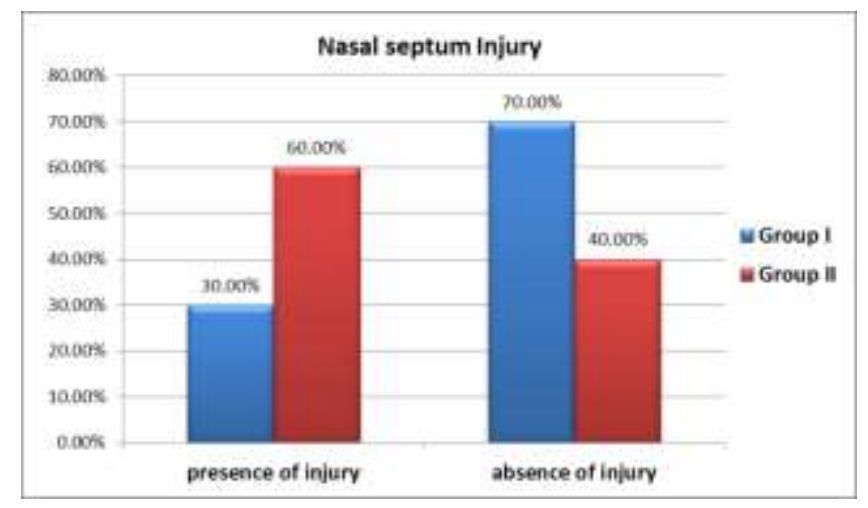

Fig. (2) Comparison between Group I and Group II regarding Nasal septum Injury.

\section{Discussion}

This research demonstrated that there was no statistically significant difference in demographic (age and sex) data between the two groups, $\mathrm{p}$ value $>0.05$.

This was in accord with Iranpour et al., [2] which indicated that the demographic information (age and gender), $\mathrm{p}$ value $>0.05$ of the two groups were not statistically significantly different.

There was a statistically significant difference in IVH complication between Group I and Group II in the present research. The IVH percentage was statistically significantly less among group I than group II as a complication (3.3 percent versus 23.3 percent respectively).

This was in line with a significant multicenter study in which invasive HFOV did not demonstrate an increase in IVH [14] and research in non-invasive HFOV on this morbidity are rare.

In general, high-frequency procedures were seldom complicated $[15,4]$.

This was in accord with Iranpour et al., [2], which reported that, with a significant difference $(\mathrm{p}=0,04)$, intraventricular haemorrhage (IVH) occurred in nine instances (6,9 per cent) of NCPAP and 2 instances (3,3 per cent) of NIHFV.

Malakian et al., [16] indicated that intraventricular haemorrhage may be even reduced compared to NCPAP if HFOV is employed as the noninvasive respiratory support.

Contrary to Zhu et al., there was no significant difference [17] in the incidence of IVH between the two groups (NCPAP vs NIHFOV).

This research demonstrated that the proportion of nasal septum damage in Group I was significantly lower than group II $(30 \% \mathrm{p}=0.020)$.
This is in agreement with Zhu et al. [18], who observed that NCPAP had a larger nasal septum damage than NIHFV.

This research demonstrated that the proportion of intervention failure (intubation and ventilator need) in group I was significantly lower than in group II $(3.3 \%$, $(26.6 \%) \mathrm{p}=0.030)$

This was consistent with Iránpour et al., [2] who observed that treatment failure (intubation and ventilator need) occurred in four out of 34 (11.8 percent) neonates in the NCPAP group and none of the statistically significant neonates in the NHFOV group $(\mathrm{p}=0.03)$. $)$.

This was in accordance with Zhu et al. [17] who observed that 9 of the 37 (24.3 percent) preterm babies in nHFOV group had failed and were requiring MV while 22 of the 39 (56.4 percent). In the nHFOV group, the requirement for $\mathrm{MV}$ was considerably reduced in comparison with the nCPAP group $(24.3 \%$ vs $56.4 \%$, $\mathrm{P}<0.01)$.

The devices and nasal interfaces utilised in nHFOV are currently vary. The choice of the device and interface is dependent primarily on local customs and convenience. Bench investigations have shown that the use of short binasals is technically viable and adequate ventilation is possible. [19]

\section{Conclusion}

High-frequency nasal ventilation has a higher impact than nasal continuous positive airway pressure on infants and fewer complication. This research revealed that the length of non-invasive respiratory support was greatly shortened by high frequency nasal ventilation and the necessity for intubation was minimised compared to the continuous positive airway pressure of RDS infants. 


\section{References}

[1] A.Malakian, S.Bashirnezhadkhabaz, MR.Aramesh, M.Dehdashtian. Noninvasive high-frequency oscillatory ventilation versus nasal continuous positive airway pressure in preterm infants with respiratory distress syndrome: a randomized controlled trial. J Matern Fetal Neonatal Med.vol.33(15),pp.26012607, 2020.

[2] R.Iranpour, A.M.Armanian, Abedi . Nasal highfrequency oscillatory ventilation (nHFOV) versus nasal continuous positive airway pressure (NCPAP) as an initial therapy for respiratory distress syndrome (RDS) in preterm and nearterm infants. BMJ paediatrics open.vol.3(1),pp. e000443,2019.

[3] G.Pelligra, MA.Abdellatif, SK.Lee. Nasal continuous positive airway pressure and outcomes in preterm infants: a retrospective analysis. Paediatr Child Health.vol.13,pp.99103, 2008.

[4] S.Aktas, S.Unal, M.Aksu. Nasal HFOV with Binasal cannula appears effective and feasible in ELBW newborns. J Trop Pediatr.vol.62,pp.1658,2016 .

[5] E.Bancalari, N.Claure. Advances in respiratory support for high risk newborn infants. Matern Health Neonatol Perinatol.vol.1,pp.1-9, 2015.

[6] SE.Courtney, DJ.Durand, JM.Asselin. Pro/con clinical debate: high-frequency oscillatory ventilation is better than conventional ventilation for premature infants. Crit Care.vol.7,pp.423-6, 2003.

[7] K.Galmén, P.Harbut, J.Freedman. The use of high-frequency ventilation during general anaesthesia: an update. F1000Res.vol.6,pp.2-55, 2017.

[8] B.A.Yoder, K.H.Albertine, DM.Null . Highfrequency ventilation for non-invasive respiratory support of neonates. Seminars in fetal \& neonatal medicine. vol. 21(3),pp. 16273, 2016.

[9] AB.Froese, PR.McCulloch, M.Sugiura. Optimizing alveolar expansion prolongs the effectiveness of exogenous surfactant therapy in the adult rabbit. Am Rev Respir Dis.vol.148,pp.569-77,1993.

[10] A.Mukerji, M.Finelli, J.Belik. Nasal high-frequency oscillation for lung carbondioxide clearance in the newborn. Neonatology.vol. 103,pp.161-5,2013.

[11] HS.Fischer, K.Bohlin and C.Bührer. Nasal high-frequency oscillation ventilation in neonates: a survey in five European countries. Eur J Pediatr.vokl. 174,pp. 465-71,2015.

[12] M.Nelle, EP.Zilow, O.Linderkamp. Effects of high-frequency oscillatory ventilation on circulation in neonates with pulmonary interstitial emphysema or RDS. Intensive Care Med.vol.23.pp.671-6,1997.
[13] R. Levesque. SPSS Programming and Data Management: A Guide for SPSS and SAS Users, SPSS Inc. Chicago Ill. PDF ISBN.vol. 1-,pp.56827390-8,2007.

[14] SE.Courtney, DJ.Durand, JM.Asselin , ML.Hudak. High-Frequency oscillatory ventilation versus conventional mechanical ventilation for very-low-birth-weight infants. $\mathrm{N}$ Engl J Med .vol.347,pp.643-52,2002.

[15] TE.Wiswell, LJ.Graziani, MS.Kornhauser. High-Frequency jet ventilation in the early management of respiratory distress syndrome is associated with a greater risk for adverse outcomes. Pediatrics .vol.98,pp.1035-43,1996.

[16] A.Malakian, S.Bashirnezhadkhabaz, MR.Aramesh and Dehdashtian. Noninvasive high-frequency oscillatory ventilation versus nasal continuous positive airway pressure in preterm infants with respiratory distress syndrome: a randomized controlled trial. J Matern Fetal Neonatal Med .vol.8,pp.1$151,2018$.

[17] X-W.Zhu, J-N.Zhao, Tang S-F,Yan. Noninvasive high-frequency oscillatory ventilation versus nasal continuous positive airway pressure in preterm infants with moderate-severe respiratory distress syndrome: a preliminary report. PediatrPulmonol.vol.52,pp.1038-42, 2017.

[18] X.W.Zhu, Y.Shi, L.P.Shi. Non-invasive highfrequency oscillatory ventilation versus nasal continuous positive airway pressure in preterm infants with respiratory distress syndrome: Study protocol for a multi-center prospective randomized controlled trial. Trials.vol.19(1),pp. $319,2018$.

[19] D.De Luca, M.Piastra, D.Pietrini and G.Conti. Effect of amplitude and inspiratory time in a bench model of non-invasive HFOV through nasal prongs. Pediatr Pulmonol. vol. 47,pp. 1012-18,2012. 